Al Risalah : Jurnal Studi Agama Dan Pemikiran Islam | Vol 12 No. 2 (2021)

\title{
HAPPY LIFE STYLE (HAYATAN TAYYIBAH) FROM THE QUR'ANIC PERSPECTIVE
}

\section{POLA HIDUP BAHAGIA (HAYATAN TAYYIBAH) MENURUT PERSPEKTIF AI-QUR'AN}

\author{
P-ISSN: 2085-5818 | E-ISSN: 2686-2107 \\ https://uia.e-journal.id/alrisalah/article/view/1239 \\ DOI: 10.34005/alrisalah.v11i1.1239
}

Naskah Dikirim:15-02-2021 Naskah Direview: 15-02-2021 Naskah Diterbitkan: 17-06-2021

\author{
Abdul Hadi \\ Universitas Islam As-Syafiiyah \\ abdulhadi.fai@uia.ac.id
}

\begin{abstract}
Islamic lifestyle mean is amount of topics and issues that satisfies Islam in human life, if we want to see that our lifestyle Islamic or not, we have to put some standart to evaluate it. But beside that, we must know rightly the concept and reality of the Islamic way of life. The standard of behavior in the Muslim community should be based on the principles of Islamic teachings, and the most important criteria for Islamic lifestyle based on the hole submission of God and the rule of Islamic values in life. So we should be base on Islamic and Quranic teaching in personal life and social ones, and in this case we can be assured that Islam being our life style.
\end{abstract}

Keywords: Lifestyle, Happiness, Quranic Perspective, Hayatan Tayyibah

Abstrak: Yang dimaksud dengan gaya hidup islami adalah banyaknya topik dan isu yang memuaskan Islam dalam kehidupan manusia, jika kita ingin melihat apakah gaya hidup islami atau tidak, kita harus menempatkan suatu standart untuk mengevaluasinya. Namun disamping itu, kita harus mengetahui dengan benar konsep dan realita jalan hidup Islam.

Standar perilaku dalam masyarakat Muslim harus didasarkan pada prinsip-prinsip ajaran Islam, dan kriteria terpenting gaya hidup Islami berdasarkan lubang ketaatan Tuhan dan kaidah nilainilai Islam dalam kehidupan. Jadi kita harus mendasarkan pada ajaran Islam dan Alquran dalam kehidupan pribadi dan sosial, dan dalam hal ini kita dapat yakin bahwa Islam menjadi gaya hidup kita.

Kata Kunci: Pola Hidup; Kebahagiaan; Perspektif Al-Quran; Hayatan Tayyibah

Abdul Hadi | Pola Hidup Bahagia (Hayyatan Tayyibah) Menurut Perspektif Al Qur'an 


\section{A. PENDAHULUAN}

Manusia dalam memahami kehidupan sangat beragam, ada yang melihatnya dengan kaca mata yang sempit dan ada yang luas, dan itu sangat tergantung pada pemahaman dan persepsinya terhadap kehidupan ini. Dunia ini dan gemerlapnya adalah segala-galanya dan tumpuan kehidupanya bagi orang yang tidak berfikir pada kehidupan akhirat, hal ini yang mematikan misi utama eksistensinya agar menjadi khalifah di bumi dalam wujud membangun peradaban dan kemanusiaan. Berbeda dengan orang yang jauh dan terbuka pola pikiranya untuk kehidupan di alam setelah dunia ini, ia bersiaga menyiapkan bekal menuju kehidupan alam tersebut dengan harus memilih jalan yang lurus, menjalani perintah Allah dan menjauhi larangaNya, tentu dengan memilih jalan ini akan berdampak positif bagi lingkungan dan dirinya dan bahkan pada kebahagiaanya baik di dunia maupun kelak di sana.

Dalam mengarungi kehidupan dunia ini, Islam mengajarkan pada setiap mukmin agar pola hidupnya untuk tidak berlebihan dalam hal apapun, termasuk juga dalam hal ibadah, sehingga ia bisa meraih bahagia. Tidak ditemukan dalam Islam ajaran yang menyuruh berkorban untuk dunia atau berkorban untuk akhirat saja, karena konsep dalam Islam tidak memandang kontradiktif keduanya. ${ }^{1}$ Kebahagian manusia di akhirat sangatlah terkait dengan tingkat kebaikanya selama di dunia. Barang siapa sesat di dunia niscaya akan sesat di akhirat. Allah SWT berfirman:

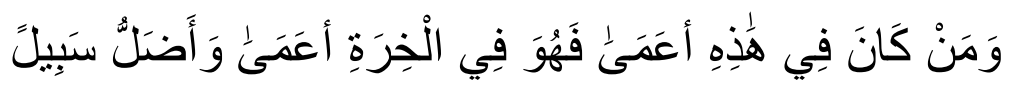

Dan barangsiapa yang buta (hatinya) di dunia ini, niscaya di akhirat (nanti) ia akan lebih buta (pula) dan lebih tersesat dari jalan (yang benar). (QS. Al-Isra: 72)

\section{B. PEMBAHASAN}

\section{Makna Pola Hidup Bahagia Menurut Al-Qur'an}

Semua bersepakat bahwa hayat tayyibah adalah kebahagian hidup yang menjadi tumpuan dan tujuan utama setiap manusia. Mereka berlari mengejar, berjuang tanpa henti demi meraih kebahagiaan dalam hidupnya, namun

1 . Abdul Hamid As-Saeh, 1998. (أنماط الحياة الإسلامية ودور ها فى تنمية الصحة) WHO Midle Est, Amman. H..2

Abdul Hadi | Pola Hidup Bahagia (Hayyatan Tayyibah) Menurut Perspektif Al Qur'an 
mereka berbeda-beda dalam memilih media dan sarana agar meraih jalan kebahagiaan itu. Perbedaan tersebut bisa terjadi dalam kontek kehidupan berbangsa, bernegara, bermasyarakat, dan bahkan dalam anggota keluarga, semuanya memiliki jalan dan kecendrungan yang berbeda dalam mewujudkan kebahagian. $^{2}$

Sepanjang sejarah manusia mereka memiliki pemahaman tersendiri tentang pola hidup bahagia, beberapa golongan melihatnya terletak pada rizki dan harta yang melimpah ruah, pada jabatan, ketenaran, berbangga dengan keluarga, dll. Namun Allah SWT dalam AI-Qur'an ${ }^{3}$ telah memberikan definisi tersendiri dalam memandang hal tersebut agar menjadi tuntunan bagi manusia, sebagaiman disebutkan dalam firman-Nya:

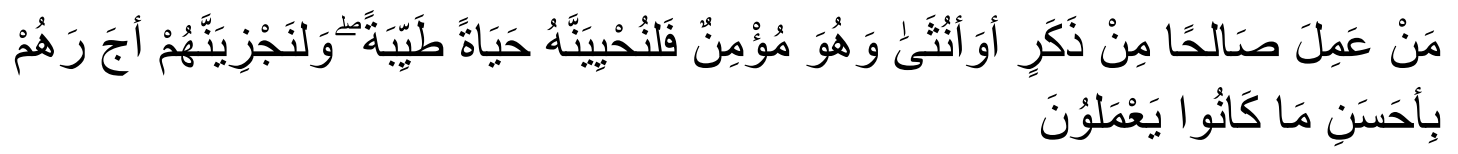

Barangsiapa yang mengerjakan amal saleh, baik laki-laki maupun perempuan dalam keadaan beriman, Maka Sesungguhnya akan kami berikan kepadanya kehidupan yang baik dan Sesungguhnya akan kami beri balasan kepada mereka dengan pahala yang lebih baik dari apa yang Telah mereka kerjakan. (QS. An Nahl: 97)

Ada dua syarat mutlak yang harus dipenuhi agar meraih hidup bahagia, Bahagia di dunia dalam firmaNya: "حياة طيبة"dan bahagia di akhirat dalam ayat berikutnya:

$$
\text { . ولنجزينهم أجر هم بأحسن ما كانوا يعملون . }
$$

Untuk meraih bahagia dalam kehidupan dunia akhirat harus memenuhi dua syarat pokok berikut:

a. Iman pada Allah

b. Berbuat baik (amal sholeh). ${ }^{3}$

2 . Ayatullah Moh. Taqiyuddin Misbah)(نمط الحياة الإسلامية، الضرورات والنقائص) Ma'rifah Nasyirat.ir.note Iran,.2665 3 . Mohammad Ratib An-Nablisi (الحياة الطيبة والمعيشة ضنكا) www.nabulsi.com/blue/ar/art.php?art...id.

3 . Mohammad Ratib An-Nablisi (Ibid)

Abdul Hadi | Pola Hidup Bahagia (Hayyatan Tayyibah) Menurut Perspektif Al Qur'an 
Kandungan ayat diatas sangat luas dan berlaku sepanjang masa. Siapa saja, kapan saja, jenis kelamin apa saja, profesi apa saja dari anak cucu Adam yang berbuat baik dan beriman dengan benar akan dijamin bahagia hidupnya di dunia dan di akhirat.

\section{Mewujudkan Hidup Bahagia Cara Islam}

Dalam perspektif Islam, kehidupan yang bahagia ketika seseorang dalam kondisi sehat jasmani dan rohani, memiliki perasaan ridho dan qonaah, dan hal ini bisa muncul karena mempunyai prilaku yang menjaga keseimbangan dan kesederhanan dalam cara makan, minum, beraktifitas, persepsi diri dan pergaulan lain.

Diantara beberapa pola kehidupan yang islami menurut Mohammad Haisyam Al Khayyat harus melakukan tiga hal berikut:

a. Menjaga Kesehatan.

b. Menjauhkan hal yang mudhorat pada diri sendiri dan orang lain.

c. Bersosialisasi dengan masyarakat. ${ }^{4}$

Ketiga hal tersebut atas dipandang sangat urgent karena sangat erat dengan pola kehidupan setiap orang sebagai individu maupun anggota masyarakat.

\section{1) Kesehatan :}

Islam memandang kesehatan sebagai nikmat besar yang diberikan Allah pada hamba-hambaNya. Karenanya Rasulullah SAW bersabda:

$$
\text { نعتان مغبون فيهما كثير من الناس: الصحة والفراغ }
$$

Dua nikmat yang banyak terlupakan oleh banyak manusia yaitu: Sehat dan kesempatan. ${ }^{5}$

Nikmat sehat akan dimintai pertangung jawabnya di depan Allah. Hal itu telah ditegaskan oleh Rasulullah dalam sabdanya:

4. Abdul Hamid As-Saeh (Ibid) h.55

5. Mohammad Haisyam Al Khayyat, 1984. (فقه الصحة) WHO Midle Est, Amman. h.5.

Abdul Hadi | Pola Hidup Bahagia (Hayyatan Tayyibah) Menurut Perspektif Al Qur'an 
"Sesungguhnya hisab pertama kali dihari kiamat bagi seseorang, adalah diajukan pertanyaan Allah; Tidakkah aku telah berikan kesehatan atas fisikmu"? Dan Rasulullah SAW. bersabda: "Setiap hamba di hari kiamat senantiasa akan diajui dengan pertanyaan soal usia dihabiskan untuk apa? Soal ilmu digunakan buat apa? Soal harta dapat dari sumber yang mana? Dan bagaimana dengan infaqnya? Dan mengenai jasad sampai binasa diguanakan buat apa?".

Dalam Alqur'an dan Hadits terdapat banyak pelajaran tentang tata cara menjaga kesehatan tubuh dengan gamblang diantaranya sebagaimana berikut:

\section{a) Wudhu'}

Islam mewajibkan berwudhu'ketika sudah batal, dan mendorong agar memperbanyak melakukanya sebelum berbagai akitifitas. Rasulullah SAW. sebagaiman riwayat Imam Tirmidhi melakukan wudhu'setiap mau melaksanakan sholat. Orang yang sedang junub disunnahkan agar berwudhu terutama ketika mau makan atau tidur, atau hendak berhubungan badan kembali dengan pasanganya, ketika sedang marah, berghibah, masuk Masjid, adzan, berkhotbah, berziarah ke kuburan, menyentuh dan membawa jenazah, dan ketika mau membaca Alqur'an. ${ }^{6}$

\section{b) Mandi}

Diantara beberapa cara untuk menjaga kesehatan dalam Islam adalah perintah melakukan mandi, dan bahkan wajib hukumnya bagi orang yang junub, Allah SWT. dalam QS: Al Maaidah 6 memerintahkan:

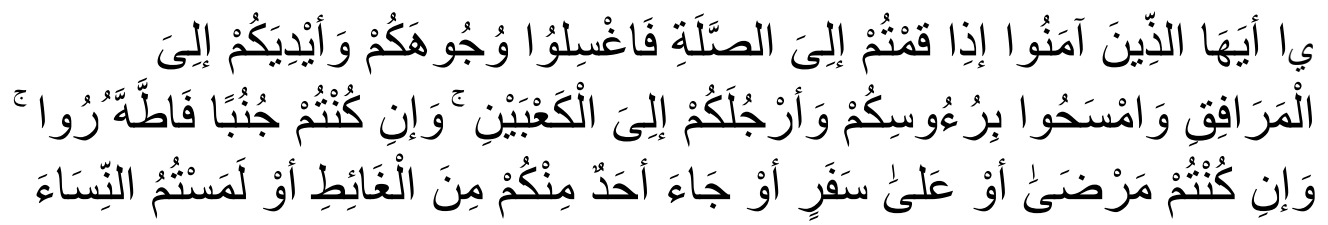

6 . Abi Isa Mohammad bin Isa bin Surah Atturmudzi, 2005. سنن الترميذي) Darul Hadits Kairo. H. .284

Abdul Hadi | Pola Hidup Bahagia (Hayyatan Tayyibah) Menurut Perspektif Al Qur'an 


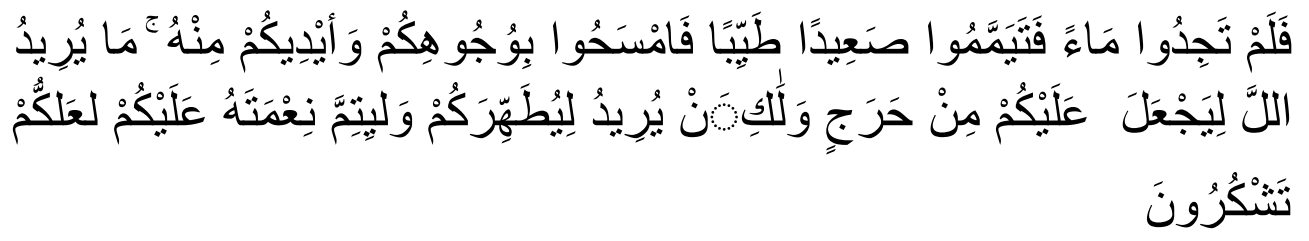

Dan jika kamu junub Maka mandilah

Rasulullah SAW mendorong ummatnya agar mandi besar di hari Jum'ah, lebaran, ihram, habis memandikan mayat, sholat istisqo, gerhana, i'tikaf, perubahan bau badan, dan mau berkumpul dengan orang. Perintah itu tidak terbatas pada kebersihan fisik secara umum, namun juga kebersihan pada anggota tubuh tertentu seperti mencuci kedua tangan sebelum makan, memotong kuku, membersihkan kaki, mulut, berkumur, dan bersiwak, sebagaimana dalam sabdanya:

$$
\text { لولَ أن أنثق على أمتي لأمرتهم بالسواك عند كل صلة. }
$$

Andaikan tidak memberatkan pada ummatku, niscaya aku perintahkan mereka agar bersiwak dalam setiap sholatnya. ${ }^{7}$

c) Perintah membersihkan telinga, kedua mata, dan rambut.

Rasulullah SAW bersabda: "Barang siapa yang dirinya dikarunia rambut, maka perihalah dengan baik." ${ }^{8}$ Dan perintah membersihkan alat kelamin, Siti Aisyah RA mengajarkan pada istri-istri kaum muslimin dalam ungkapanya: "Suruhlah suami-suami kalian agar bersuci dengan air karena aku malu untuk mengatakan kepada mereka, karena rasulullah melakukan hal tersebut."

\section{d) Mengkonsumsi Makanan Bergizi}

Hal ini dapat dilakukan dengan dua cara:

Yang pertama: Mencari makanan yang baik, dan menjauhi makanan yang tidak baik. Firman Allah:

7. Abi Abdillah Mohammad bin Ismail Al Bukhori)(الجامع الصحيح) Darul Hadits Kairo. H 351.

8. Abi Daud Sulaiman bin Asyab As Sajastani: 1973. سنن أبي دود) Darul Hadits Suria. H. 394

9 . Abi Isa Mohammad bin Isa bin Surah Atturmudzi (lbid). H.108

Abdul Hadi | Pola Hidup Bahagia (Hayyatan Tayyibah) Menurut Perspektif Al Qur'an 


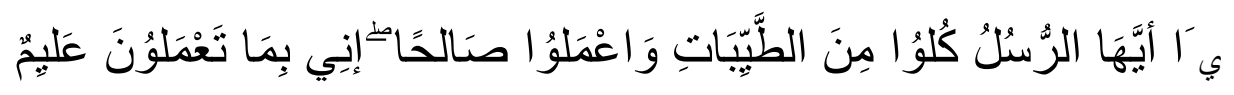

Hai rasul-rasul, makanlah dari makanan yang baik-baik, dan kerjakanlah amal yang saleh. Sesungguhnya Aku Maha mengetahui apa yang kamu kerjakan. (QS. Al Mu'minun: 51)

Yang kedua: Tidak boleh menghindar dari makanan yang baik. Firman Allah:

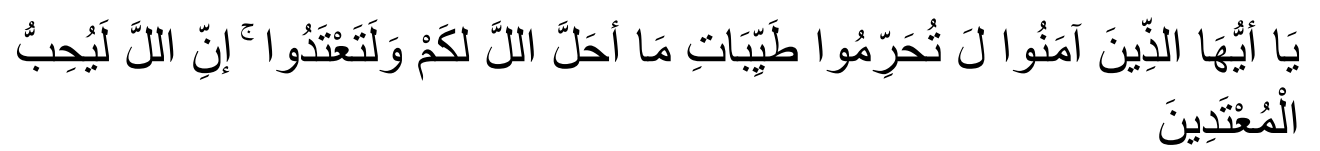

Hai orang-orang yang beriman, janganlah kamu haramkan apa-apa yang baik yang Telah Allah halalkan bagi kamu, dan janganlah kamu melampaui batas. Sesungguhnya Allah tidak menyukai orang-orang yang melampaui batas. (QS. Al Maaidah: 87)

Yang Ketiga: Tidak boleh berlebihan mengkonsumsi makanan. Rasulullah SAW bersabda "Bani Adam tidak mengisi penuh sebuah wadah yang lebih jelek dari perutnya, dan cukuplah baginya ukuran kecil yang $b$ isa menguatkan tulang punggungnya". ${ }^{10}$

\section{Menghindari hal yang berbahaya/ modarat pada diri, atau pada orang lain.}

Pernyataan ini adalah hadits Rasul yang diriwayatkan oleh Addaru Kutni dari Uman bin Yahya dan dari bapaknya. ${ }^{11}$ Sedangkan Ibnu Majah dan Imam Ahmad dari Jabir bin Alja'fi, menguatkan terhadap hadits diatas namun dengan bentuk bahasa yang lain, sebagaimana sabda Rasul: "Dilaknat orang yang membuat modhorat pada orang mukmin atau memperdayanya". ${ }^{12}$

Syekh Rasyid Ridho mendifinisikan"Mudhorat atau membuat mudhorat" dalam tafsirnya yaitu: Menghilangkan hal yang dianggap berbahaya bagi individu dan kolektif. Kemudian dari difinisi ini muncul konsep "menolak segala

\footnotetext{
10. Abi Isa Mohammad bin Isa bin Surah Atturmudzi(lbid) pg. 317

11. Abi Abdillah Mohammad bin Yazid Al Kuzaini(سنن إين ماجة) Darul Hadits Suria, pg 1311.

12 .Abi Isa Mohammad bin Isa bin Surah Atturmudzi(lbid) pg. 106.
}

Abdul Hadi | Pola Hidup Bahagia (Hayyatan Tayyibah) Menurut Perspektif Al Qur'an 
bentuk kerusakan dan menjaga setiap hal yang maslahat, menjaga segala hal yang diungkapkan oleh nash-syara' dan tujuanya. ${ }^{13}$

Dalam dunia kesehatan konsep ini mengandung hal-hal berikut:

(1). Membuat Mudhorat/bahaya pada diri sendiri: Hukumnya adalah haram dengan berdasarkan pada firman Allah:

195. Dan janganlah kamu menjatuhkan dirimu sendiri ke dalam kebinasaan, dan berbuat baiklah, Karena Sesungguhnya Allah menyukai orang-orang yang berbuat baik. (Al-Quran)

Dan sabda Rasulullah: " لَضرر" tidak ada mudhorat, dalam arti lain: tidak boleh bagi seorang muslim membiarkan dirinya pada bahaya penyakit dalam bentuk apapun.

Islam mewajibkan kepada setiap muslim agar menjaga kesehatan dengan cara berikut:

Pertama: Memberi perhatian pada hal-hal yang bermanfaat untuk kesehatan seperi mengkonsumsi makanan dan minuman dengan baik, dan tidak berlebihan, serta berolah raga dan seterusnya.

Kedua: Menghindari hal-hal yang menimbulkan penyakit, karena dengan penjagaan bisa membuat pencegahan, termasuk juga menghindari sumbersumber yang menimbulkan penyakit seperti mendekati hal yang menuju pada perzinahan dan semua jenis keburukan. Allah SWT. Mengingatkan supaya tidak mendekati sumber-sumber kemaksiatan dalam firmaNya:

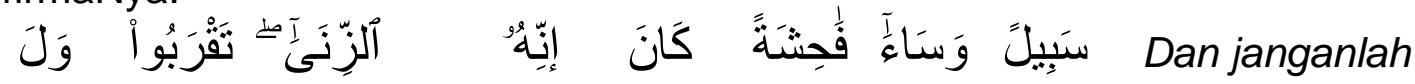
kamu mendekati zina; Sesungguhnya zina itu adalah suatu perbuatan yang keji. dan suatu jalan yang buruk. (QS: Al Isra': 32)

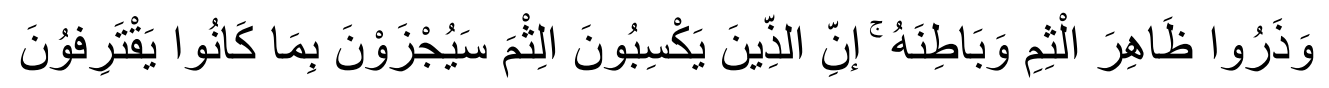

Dan tinggalkanlah dosa yang nampak dan yang tersembunyi. Sesungguhnya orang yang mengerjakan dosa, kelak akan diberi pembalasan (pada hari kiamat), disebabkan apa yang mereka Telah kerjakan. (QS. Al An'Am: 120)

13. Rasyid Ridho (تفسير المنار) Haiah Misriyyah Ammah Lil Kitab, Kairo 1973, pg 100

Abdul Hadi | Pola Hidup Bahagia (Hayyatan Tayyibah) Menurut Perspektif Al Qur'an 
Menurut Sayyid Rosid Ridho yang dimaksud dengan dosa adalah setiap hal-hal yang membuat mudhorat/bahaya pada diri dan harta atau lainya, akan tetapi mudhorat dan kerusakan yang terberat ketika membuat mudhorat kepada masyarakat. Seperti narkoba, dan hal-hal lain yang bisa merusak mental. $^{14}$

Ketiga: Setiap muslim hendaknya berobat jika mengindap sebuah penyakit, hal ini ditegaskan oleh Rasulullah dalam sabdanya:

"Berobatlah kalian, karena Allah SWT. tidak meletakkan sebuah penyakit kecuali Dia telah meletakkan obatnya. ${ }^{15}$

\section{Membuat mudhorat pada anggota keluarga}

Termasuk dari perbuatan yang berbahaya terhadap orang lain adalah berbuat mudhorat pada kedua orang tua, anak dan istri. Islam telah berwasiat pada manusia agar berbuat baik pada kedua orang tua, sebagaimana firman Allah dalam

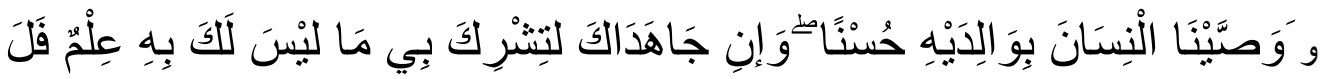

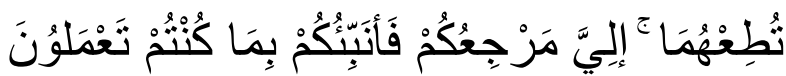

Dan kami wajibkan manusia (berbuat) kebaikan kepada dua orang ibubapaknya. dan jika keduanya memaksamu untuk mempersekutukan Aku dengan sesuatu yang tidak ada pengetahuanmu tentang itu, Maka janganlah kamu mengikuti keduanya. Hanya kepada-Ku-lah kembalimu, lalu Aku kabarkan kepadamu apa yang Telah kamu kerjakan. (QS. Al Ankabuut: 8) Rasulullah SAW ${ }^{16}$ melarang melakukan hal yang membuat cacat, durhaka pada ibu,dan mengubur anak perempuan hidup-hidup, serta berwasiat kepada suami akan istrinya dalam sabdanya: استوصو بالنساء خيرا

Artinya: "Perlakukanlah kaum perempuan dengan baik". Kemudian rasul menambahkan:

\footnotetext{
14. Rasyid Ridho (lbid) pg. 115

15 .Abi Abdillah Mohammad bin Yazid Al Kuzaini (ibid) H. 1317.

16. ${ }^{17}$. Abi Abdillah Mohammad bin Yazid Al Kuzaini(ibid) Darul Hadits, pg 1313.
}

Abdul Hadi | Pola Hidup Bahagia (Hayyatan Tayyibah) Menurut Perspektif Al Qur'an 


$$
\text { اللهم أخرج حق الضعفين: اليتيم و المر أة }
$$

Artinya: Ya..Allah susungguhnya aku membuat dosa terhadap orang yang lalai pada haknya dua hamba yang lemah yaitu: Anak yatim, dan perempuan.

Islam mengharamkan berbuat lalai memberikan hak-hak orang tua dan anak, menjaga kesehatanya dan melakukan pencegahan dari berbagai penyakit. Hal ini telah diperingatkan oleh Allah:

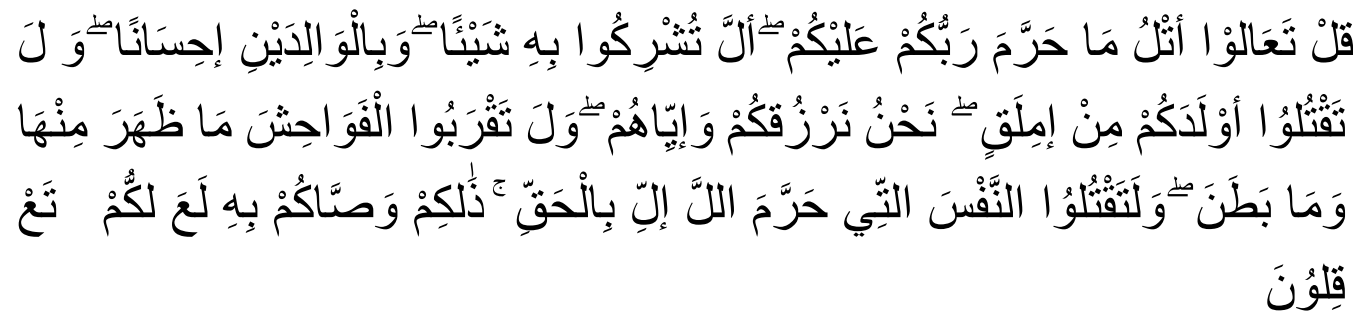

Katakanlah: "Marilah kubacakan apa yang diharamkan atas kamu oleh Tuhanmu yaitu: janganlah kamu mempersekutukan sesuatu dengan Dia, berbuat baiklah terhadap kedua orang ibu bapa, dan janganlah kamu membunuh anak-anak kamu Karena takut kemiskinan, kami akan memberi rezki kepadamu dan kepada mereka, dan janganlah kamu mendekati perbuatan-perbuatan yang keji, baik yang nampak di antaranya maupun yang tersembunyi, dan janganlah kamu membunuh jiwa yang diharamkan Allah (membunuhnya) melainkan dengan sesuatu (sebab) yang benar". demikian itu yang diperintahkan kepadamu supaya kamu memahami(nya). (QS. Al-An'am: 151)

\section{3) Membuat mudhorat pada orang lain}

Melakukan tindakan yang berbahaya pada orang lain, terutama tetangga dekat hukumya haram, karena rasulullah melarang perbuatan tersebut dalam sabdanya: ${ }^{17}$

17 .Abi Isa Mohammad bin Isa bin Surah Atturmudzi(lbid) pg. 106.

Abdul Hadi | Pola Hidup Bahagia (Hayyatan Tayyibah) Menurut Perspektif Al Qur'an 


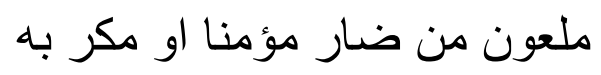

"Dilaklat orang yang membuat mudhorat atau menipu orang mu'min". Dalam و اللَّ لَلَيؤمن، واللَّ لَيؤمن، قالو من هو

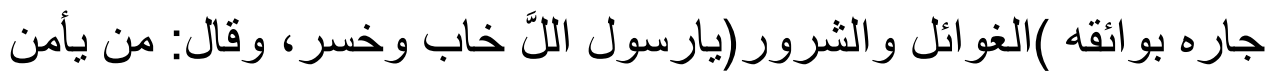

Demi Allah dia tidak beriman, demi Allah dia tidak beriman, para sahabat berkata: Siapa dia orang yang hina dan rugi wahai rasulullah? Rasul menjawab: Orang yang tidak membuat tentram tetangganya karena tipu dan perbuatan jahatnya. ${ }^{18}$

Membuat mudhoraot pada orang lain hukumnya adalah haram. Dasarnya firman Allah:

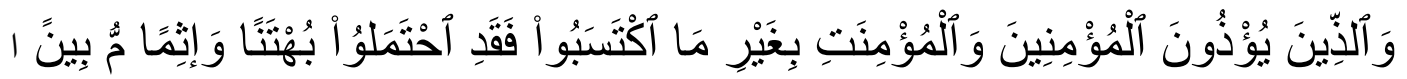

Dan orang-orang yang menyakiti orang-orang yang mukmin dan mukminat tanpa kesalahan yang mereka perbuat, Maka Sesungguhnya mereka Telah memikul kebohongan dan dosa yang nyata. (QS: Al Ahzab 58)

Rasulullah SAW seringkali memperingatkan dari hal-hal yang menyebabkan bahaya dan menyakitkan pada anggota masyarakat, dan menyuruh agar membuat penjagaan yang kuat dan bisa mencegah mereka dari bahaya tersebut. Hal itu dapat dilihat dalam sabdanya:

Barang siapa yang berjalan dengan membawa senjata tajam di Masjid atau di Pasar kami, maka hendaknya ia ditangkap atau diambil senjatanya, supaya salah satu dari kaum Muslimin tidak terkena bahaya dari senjata tadi. ${ }^{19}$

\section{Bersosialisasi dengan masyarakat.}

Rasulullah SAW bersabda: Orang mukmin yang bergaul dengan manusia dan bersabar dari perbuatan mereka yang menyakiti dirinya, lebih baik dari

\footnotetext{
18 . Abi Husen bin Al Hajjaj Al Qusyairi An Naisaburi (صحيح مسلم) Darul Ihya Kutub Al Arabia, Kairo, pg.68.

19 .Abi Abdillah Mohammad bin Ismail Al Bukhori (ibid) . H. 315 .
}

Abdul Hadi | Pola Hidup Bahagia (Hayyatan Tayyibah) Menurut Perspektif Al Qur'an 
orang Mukmin yang menjauhi mereka dan tidak sabar dari perbuatan mereka yang menyakitinya. ${ }^{20}$

Dalam Islam bersosialiasi dengan masyarakat sangat urgent untuk menjaga kesehatan, namun dalam hal ini ada beberapa faktor pendukungnya antara lain:
a) Saling ketergantungan
b) Saling tolong menolong
c) Mandiri
d) Berbuat kebaikan.

\section{a) Saling Ketergantungan}

Dalam konsep Islam yang maksud dengan saling ketergantungan bukan setiap individu larut dalam klompok masyarakat, namun setiap individu saling berpegang erat seperti keterkaitan struktur sebuah bangunan. Hal itu ditegaskan oleh Rasulullah SAW. dalam sabdanya:

Seorang Mukmin terhadap Mukmin yang lain bagaikan sebuah bangunan yang saling menguatkan diantara satu dengan lainya. ${ }^{21}$

Dalam terminologi Islam bahasa yang pantas untuk mengungkapkan hal tersebut adalah"ذات البين"Artinya (permusuhan). Imam Qurtubi menyebutkan maksud dari term ini adalah menciptakan kondisi disa mewujudkan kesepakatan bersama. Menurut Syaikh Rosid Ridho pertalian seperti ini masuk dalam katagori ذات 22 ذاتبين

Dalam ajaran Islam kita diperintahkan untuk mendamaikan orang yang sedang bertikai, dan hukumnya adalah wajib. Bahkan dikatakan kebesaran Islam dan kesatuan Ummat sangat tergantung pada hal tersebut.

Rasulullah SAW bersabda: Tidakkah aku beritakan dengan sebuah kedudukan dimana pahalanya lebih utama dari ibadah sholat, puasa, dan zakat? Mereka berkata: Ya wahai Rasulullah, Rasul menjawab: mendamaikan

20 . Ali Jum'at, 2006. (سمات العصر) Darul Faruq,Kairo. H. 39.

21. HR.Muslim, dalam Kitab Al Birru Wattaqwa, nmr 1999.

22. Rosyid Ridho (ibid) 117.

Abdul Hadi | Pola Hidup Bahagia (Hayyatan Tayyibah) Menurut Perspektif Al Qur'an 
orang yang saling bermusuhan. Kemudian beliau menyebutkan: Kehancuran akibat dari perpecahan disebut dengan istilah alat cukur (الحالقة).23

\section{b) Saling tolong menolong}

Wajib hukumnya bagi setiap muslim agar bermanfaat bagi saudaranya dan berupaya melakukan sesuatu untuk kemaslahatannya. Islam tidak menghendaki muslim yang berbuat mudhorat dan tak peduli terhadap orang lain, dan bahkan mencabut identitasnya sebagai masyarakat muslim pada setiap individu masyrakatnya yang tidak peduli terhadap kemaslahatan orang lain. Rasulullah SAW bersabda: "Barang siapa yang acuh terhadap urusan kaum muslimin, maka ia bukan termasuk golonganku." ${ }^{4}$ Dalam sabdan lain: "Tidak beriman salah satu dari kalian hingga ia mencintai saudaranya seperti ia mencintai dirinya sendiri (dalam hal kebaikan)".

Dalam Islam ada sistem yang sangat unik dalam melestarikan kerjasama dan berbuat maslahat untuk orang lain. Hal ini tidak ditemukan dalam ajaran agama lain yaitu: Penerapan "Hukum Fardhu Kifayah" yang prinsipnya adalah: Segala apapun yang mengandung manfaat bagi masyarakat umum disebut dengan Fardhu Kifayah dalam arti lain kewajiban kolektif, akan tetapi sebagian dari anggota masyarakat saja yang dapat melaksanakan kewajiban tersebut sudah dianggap cukup, sehingga secara otomatis tidak menuntut semua orang untuk melaksanakanya. Jika tak satupun dari mereka yang melaksanakan semua memikul beban dosa.

\section{c) Mandiri}

Setiap generasi dalam masyarakat Islam seperti ranting yang keluar dari batang kayu yang tidak terbebani olehnya. Generasi Muslim tidak menambah beban anggota masyarakatnya, tapi berperan sebagai penguat mereka, dan semua bentuk dukunganya tidak terputus sehingga terbangun masyarakat kuat dan menjadi contoh untuk masyarakat lain.

23. Abu Dawud (سنن أبي دود) Darul Ihya' Kitab Arabiah, Kairo. H.39.

24. HR. Bukhori dalam Kitab Al Iman 13/1. H. 110.

Abdul Hadi | Pola Hidup Bahagia (Hayyatan Tayyibah) Menurut Perspektif Al Qur'an 
Hal ini dimaksudkan bahwasanya masyarakat muslim dalam kondisi yang tumbuh dan berkembang tanpa henti seperti yang termaktub dalam Injil. Mengenai hal ini lihat Al-Qur'an:

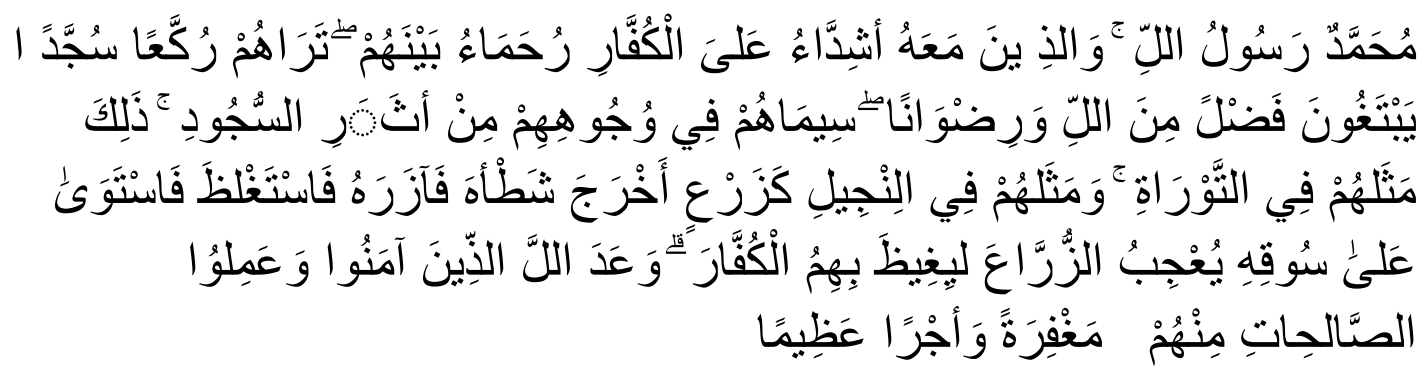

Yaitu seperti tanaman yang mengeluarkan tunasnya Maka tunas itu menjadikan tanaman itu Kuat lalu menjadi besarlah dia dan tegak lurus di atas pokoknya; tanaman itu menyenangkan hati penanam-penanamnya Karena Allah hendak menjengkelkan hati orang-orang kafir (dengan kekuatan orangorang mukmin). Allah menjanjikan kepada orang-orang yang beriman dan mengerjakan amal yang saleh di antara mereka ampunan dan pahala yang besar. (QS. Al Fath: 29)

Pada dasarnya dalam Islam setiap individu Muslim wajib memberikan kontribusi yang baik bagi masyarakatnya sehingga tidak menggantungkan kehidupanya pada pihak lain semaksimal mungkin. Seorang Muslim seperti yang telah disabdakan oleh nabi; bekerja dengan kemampuanya sendiri, sehingga bermanfaat buat dirinya dan bisa berinfak atau bersedekah. Islam juga menganjurkan pada setiap Muslim agar berusaha agar menjaga income pendapatanya. Allah berfirman

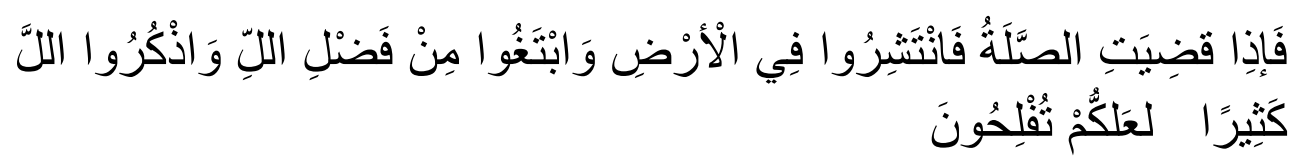

Dan carilah karunia Allah dan ingatlah Allah banyak-banyak supaya kamu beruntung. (QS. Al Jum'ah: 10)

Islam mendorong pada setiap Muslim agar bekerja sehingga bisa mendapatkan income yang berguna bagi dirinya, sehingga dapat menjaga diri dari meminta-minta pada orang lain dan merasa berkecukupan. Rasulullah

Abdul Hadi | Pola Hidup Bahagia (Hayyatan Tayyibah) Menurut Perspektif Al Qur'an 
SAW. bersabda: $\left.{ }^{25}\right)$

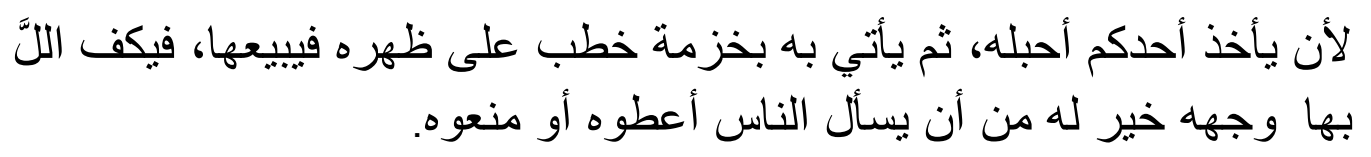

"Sekiranya diantara kalian ada yang mengambil tali yang digunakan untuk mengikat bundalan kayu yang diletakkan di punggungnya untuk di jual, sehingga karenanya Allah dapat menjaga harga dirinya adalah lebih baik daripada meminta-minta pada manusia meskipun mereka member atau menolaknya".

Dengan demikian akan tercipta masyarakat yang kuat yang memiliki tangan diatas bukan tangan dibawah. Nabi SAW bersabda:26

$$
\text { البد العليا خير من البد السفلى }
$$

Tangan yang diatas lebih baik dari tangan yang dibawah.

\section{d) Berbuat kebajikan}

Islam meletakkan prinsip dasar agar masyarakat Muslim terpelihara dengan baik dan selamat. Perinsip tersebut utamanya ada empat, sedangkan dalam hal keutamaanya bertingkat dan masing-masing tingkatan adalah hasil dampak dari tingkatan yang diatasnya. Adapun keempat prinsip tadi adalah:

1) Mendamaikan kelompok yang bertikai.

2) Melakukan hal yang positif

3) Bersedaqah

4) Berbuat kebajikan.

Tiga point dari yang pertama terangkum dari firman Allah SWT:

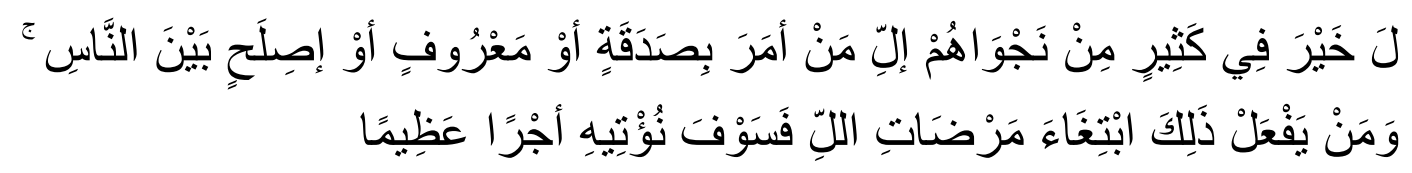

Tidak ada kebaikan pada kebanyakan bisikan-bisikan mereka, kecuali bisikanbisikan dari orang yang menyuruh (manusia) memberi sedekah, atau

25. HR. Bukhori dalam Kitab Zakat, 1445/1, pq 446
26. HR. Bukhori dalam kitab Wasaya 2750/2,pq 289.

Abdul Hadi | Pola Hidup Bahagia (Hayyatan Tayyibah) Menurut Perspektif Al Qur'an 
berbuat ma'ruf, atau mengadakan perdamaian di antara manusia. (QS. AnNisa: 114)

Sedangkan point yang keempat ditunjukkan oleh Rasulullah SAW dalam sabdanya: ${ }^{27}$

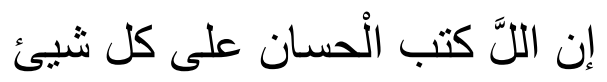

Sesungguhnya Allah memastikan agar berbuat kebaikan dalam segala hal.

Keempat prinsip diatas adalah ciri pokok masyarakat modern dan juga sebagai instrument pokok untuk menjaga kebahagianya.

\section{PENUTUP}

Para filosof sangat beragam dalam melihat pola hidup bahagia, Aristoteles, menjelaskan bahwa hanya orang yang menguasai hawa nafsunya yang bisa bahagia. Sebagai illustrasi dari dua orang yang pernah menimba ilmu dari Socrates, yaitu Aristippus dan Anthitenes. Menurut Antithenes, kebahagiaan adalah dengan meninggalkan kesenangan-kesenangan materil, karena sejatinya kebahagiaan adalah bersifat metafisik. Sebaliknya Aristippus berpendapat bahwa kebahagiaan adalah bagaimana memuaskan hasrat jasmaniyah. Akhirnya Antithenes dikenal sebagai tokoh aliran asketisme yang menekankan pencapaian kebahagiaan dengan menjauh dari kesenangankesenangan materil, sebaliknya Aristippus kemudian dikenal sebagai tokoh aliran hedonisme yang menekankan kebahagiaan dengan pemenuhan kesenangan-kesenangan materil (hedone). Berbeda dengan Islam yang melihat kebahagian itu dengan memenuhi kebutuhan materi dan immateri secara seimbang, berpedoman pada Al-Qur;an dan Sunnah, melaksanakan perintahhnya dan menjauhi laranganya, sejatinya kebahagian dalam Islam bisa diraih dengan berbekal keimanan dan beramal sholeh.

27. HR. Muslim dalam Kitab At Dabhu, 1955/3, pq 1548.

Abdul Hadi | Pola Hidup Bahagia (Hayyatan Tayyibah) Menurut Perspektif Al Qur'an 


\section{DAFTAR PUSTAKA}

Abi Daud Sulaiman bin Asyab As Sajastani(سنن أبي دود) Darul Hadits Suria, 1973, Abu Dawud (سنن أبي دود) Darul Ihya' Kitab Arabiah, Kairo.

Abi Isa Mohammad bin Isa bin Surah Atturmudzi(سنن الترميذي)Penerbit Darul Hadits Kairo, 2005

Al Bukhori Abi Abdillah Mohammad bin Ismail (الجامع الصحيح) Penerbit Darul Hadits Kairo

An Naisaburi Abi Husen bin Al Hajjaj Al Qusyairi (صحيح مسلم) Darul lhya Kutub Al Arabia, Kairo.

Mohammad Ratib An-Nablisi (ضنكا (الميشة الطيبة الحباة) www.nabulsi.com/blue/ar/art.php?art...id. As-Saeh Abdul Hamid ( أنماط الحياة (الُسلمية ودور ها فى تتمية الصحة)WHO Midle Est, Amman, 1998.

Al Khayyat Mohammad Haisyam (فقه الصحة) WHO Midle Est, Amman Yordania, 1984.

Al Kuzaini Ayatullah Moh. Taqiyuddin Misbah( نمط الحياة الُسلمية، Ma'rifah Nasyirat.ir.note Iran,.2665 (الضرور اتو النقائص

Hadi Abdul (البعد الديني في الثخصية السوية) Maktabah Madbuly, Kairo 2010

Ridho Rasyid (تفسير المنار)Penerbit Haiah Misriyyah Ammah Lil Kitab, Kairo 1973

Abi Abdillah Mohammad bin Yazid (سنن إبن ماجة) Penerbit Darul Hadits Suriah 